\title{
Fosfor-sandviç tipi dedektör sisteminin toplam gama verimi için modellenen Geant4 tabanlı GATE simülasyonu
}

\author{
Nuray Yavuzkanat ${ }^{1 *}$ (D) \\ ${ }^{1}$ Bitlis Eren Üniversitesi, Fen Edebiyat Fakültesi, Fizik Bölümü, Bitlis, Türkiye. \\ *nyavuzkanat@beu.edu.tr \\ Özet
}

Fosfor-sandviç (phosphor-sandwich ya da phoswich) (PW) tipi dedektör sistemleri nükleer fizikte aynı anda birden fazla radyasyon çeşidini ölçebilen dedektör sistemleridir. Bu dedektörlerin düşük aktiviteli çevresel radyasyon ölçümlerinde kullanılmasının yanında günümüzde üç veya iki katmanlı olarak yapılan bu dedektörler medikal görüntülemede, nükleer santrallerin ve nükleer kazalar sonrası çevresel güvenliğin sağlanmasında da kullanılmaktadır. Bu tip dedektör sistemleri birden fazla radyasyon çeşidini aynı anda ölçebilmesinin yanında PARIS gibi büyük dedektör sistemlerinde olduğu gibi farklı enerji aralığındaki gama radyasyonlarını ayırt edebilmek için de kullanılırlar. Bu kadar geniş bir kullanım alanına sahip olan PW tipi dedektör sistemlerinin kalibrasyonları için gerekli olan verimlilik eğrileri; deneysel, ampirik, analitik ve Monte Carlo (M.C) gibi dört farklı yolla tespit edilebilir. Bu çalışmada Geant4 tabanlı çalışan GATE simülasyon programında silindir şeklinde $\mathrm{Nal}(\mathrm{TI})$ ve $\mathrm{CaF}_{2}(\mathrm{Eu})$ sintilatör malzemelerini içeren phoswich dedektör sistemi modellenerek verimlilik değerleri ve toplam gama verimliliği eğrisinin fit parametreleri bulunmuştur. Phoswich dedektör sisteminin toplam gama verimi 50 keV'den 3000 keV'e kadar farklı enerjilerde izotropik olarak foton yayımlayan nokta ve disk şeklindeki radyoaktif kaynaklar için elde edilmiştir. Ayrıca bu sonuçlar literatürdeki sonuçlarla karşılaştırılmış ve sonuçların birbirleri ile uyumlu olduğu gözlenmiştir.

Anahtar Kelimeler: Fosfor-sandwich, GATE, toplam gama verimi, sintilasyon

\section{Modeling Geant4 based GATE simulation for total gamma efficiency of phoswich type detector system}

\begin{abstract}
In nuclear physics, phosphor-sandwich (phoswich) (PW) type detector systems can measure more than one type of radiation at the same time. In addition to the use of these detectors in low-activity environmental radiation measurements, these detectors, which are made with three or two layers, are also used in medical imaging, nuclear power plants and environmental safety after nuclear accidents. Being able to measure more than one type of radiation at the same time, this type of detector systems is also used to separate gamma radiations in different energy ranges as in large detector systems such as PARIS. It is necessary to obtain the total gamma efficiency curve for the calibration of the wide range of use of the PW type detector systems. It can be determined in four different methods, such as experimental, empirical, analytical, and Monte Carlo (M.C) simulation. In this study, the efficiency values and the fitting parameters were found out by modeling the phoswich detector system, including cylindrical $\mathrm{Nal}(\mathrm{TI})$ and $\mathrm{CaF} 2(\mathrm{Eu})$ scintillations, in the Geant4 based GATE simulation program. The total gamma efficiency of the Phoswich detector system has been obtained for point and disc shaped radioactive sources that emit photons isotropically at different energies from $50 \mathrm{keV}$ to $3000 \mathrm{keV}$. In addition, these results were compared with the results in the literature and it was observed that the results were compatible with each other.
\end{abstract}

Keywords: Phoswich, GATE, total efficiency, scintilation 


\section{GíRIŞ}

Fosfor-sandviç (phosphor-sandwich ya da phoswich) (PW) olarak adlandırılan dedektör sistemleri nükleer fiziğin pek çok alanında farklı amaçlar için kullanılmaktadır. Sağlık ve güvenlik açısından özellikle toprak, su ve hava gibi ortamdaki çevresel radyoaktivite ölçümlerinde büyük bir öneme sahiplerdir [1]. Düşük aktiviteli doğal kaynaklardaki ya da çevresel radyoaktivite ölçümlerinde toplam alfa, beta ve gama sayımlarında kullanılırlar [1-2]. Bir başka kullanım alanı ise nükleer reaksiyonlar sonucunda açığa çıkan farklı enerji aralığındaki gama 1şınlarını tespit edebilmek için geliştirilen PARIS gibi farklı sintilasyon malzemeleri kullanarak yapılan yeni nesil dedektörlerdir. Bu detektör 15,24 cm uzunluğundaki NaI(Tl) sintilatörü ile $5,08 \mathrm{~cm}$ uzunluğuna sahip $\mathrm{LaBr}_{3}(\mathrm{Ce})$ sintilasyon malzemesinin optiksel olarak bir araya getirilmesiyle oluşturulan yeni nesil phoswich dedektörleridir [3-4]. PARIS (Photon Array for studies with Radioactive Ions and Stable beams) radyoaktif iyonlar ve kararlı 1şınlarla çalışabilmek için geliştirilen bir foton dedektörleri dizisidir. Bu dedektörler dizisi $50 \mathrm{keV}$ 'den $40000 \mathrm{keV}$ 'e kadar geniş bir enerji aralığında etkili olmasının yanında iyi enerji çözünürlüğüne ve hızlı cevap verme süresine de sahiptir [3-4]. Son zamanlarda ise özellikle nükleer santrallerde oluşacak herhangi bir kaza sonrası aynı anda alfa-beta-gama radyasyonunu ölçebilen tek bir dedektör ihtiyacını karşılamak ve yeni tıbbi-moleküler görüntüleme için geliştirilen PW tipi dedektör sistemleri mevcuttur [5-6]. Bu üç katmanlı dedektör sisteminde alfa ölçümü için plastik bazlı sintilasyon kullanılırken, beta ve gama radyasyonunun ölçümünde ise farklı oranlarda ilave edilmiş seryum (Ce) elementi içeren GSO sintilatör malzemesi kullanılmıştır [5-6]. Ayrıca iki katmanlı PW tipi dedektörlerin tıbbi görüntülemede beta-gama prob gibi kullanım alanları da mevcuttur [79].

Çevresel radyoaktivite ölçümlerinde ve bazı nükleer reaksiyon deneylerinde kullanılan dedektör sistemlerinin enerji kalibrasyonları kadar dedektör verimi kalibrasyonlarının da mutlaka yapılması gereklidir. Bir dedektörün toplam gama verimliliği deneysel, ampirik, analitik ve Monte Carlo (M.C) gibi dört farklı yolla tespit edilebilir [10]. Deneysel kalibre işlemleri labaratuvarlarda bulunan standart gama kaynakları kullanılarak yapılmaktadır. Dedektör sisteminin gama sayım verimliliğini tüm gama enerjileri için deneysel olarak belirlemek sınırlı sayıda tek enerjili gama yayınlayan radyoizotopların olmasından dolayı neredeyse imkansızdır [1,11]. Ayrıca bu standart radyoaktif kaynaklar oldukça pahalı ve uzun süren laboratuvar çalışmaları gerektirir [11]. Deneysel olarak tanımlanamayan ara enerjideki gama-ışınlarının verimliliğinin tanımlanması iki yolla mümkündür. Ya deneysel olarak elde edilen sınırlı sayıdaki gama sayım verimliliği fit edilerek elde edilen analitik denklem kullanılır. Ya da gama-ışınının madde ile etkileşim mekanizmaları temelinde oluşturulan bilgisayar algoritmaları kullanılarak tüm gama enerjiler için dedektör verimliliği elde edilir [1,12]. Monte Carlo simülasyon metodu medikal fizikten parçacık fiziğine kadar çok geniş bir alanda kullanılır. Günümüzde en iyi bilinen M.C. kodlarının başında Geant4 gelirken ayrıca PENELOPE, MCNP ve GATE gibi uygulama alanlarına göre farklılık göstererek özelleştirilmiş kodlarda mevcuttur [12]. Geant4 maddeden geçen ve parçacıklarla etkileşimleri gerçekleştiren $\mathrm{C}++$ dilinde çalışan bir yazılımdır. GATE ise Geant4'u çalıştırabilen bir arayüz programıdır ve kullanımı için ileri derecede bir $\mathrm{C}++$ programlama dilini bilmeyi gerektirmez. GATE, uluslararası kurumların işbirliği ile sürekli geliştirilen ve Geant4'un yenilenmesine bağlı olarak sürekli yenilenen bir yazılım programıdır [13].

Bu çalışma Geant4 tabanlı çalışan GATE simülasyon programında PW tipi dedektör siteminin toplam gama verimi için geliştirilmiş Monte Carlo (M.C) modellemesini içermektedir. PW tipi dedektör sistemlerinin kullanım alanlarının oldukça fazla olmasına ve popülerliğini hala koruyor olmasına rağmen PW dedektörlerinin gama sayım verimliliği üzerine GATE simülasyonu ile yapılmış herhangi bir çalışma mevcut değildir. Bu modellenmiş GATE simülasyonunun bilgisayarda hesaplama süresi oldukça kısa ve yazılımı da kolay olduğundan yeni nesil PW dedektör sistemlerine de kolay uygulanabilirliği vardır. Simülasyonda izotropik olarak farklı enerji aralıklarında foton yayınlayan nokta ve disk olmak üzere iki farklı kaynak geometrisi tanımlanmıştır. Laboratuvar koşullarında Planchette holder'lar (tutturucular) kullanılarak dedektör kaynak mesafelerinin nasıl ayarlandığı Şekil 1'de gösterildiği gibidir. Literatürdeki değerlerle karşılaştırabilmek için dedektör ile kaynak arasındaki mesafe (D) $0,43 \mathrm{~cm}, 0,87 \mathrm{~cm}$ ve $1,05 \mathrm{~cm}$ olmak üzere üç farklı mesafe için toplam gama sayım verimliliği bulunmuştur. Elde edilen sonuçlar 
literatürdeki diğer Monte Carlo teknikleri ve analitik yaklaşımla elde edilen sonuçlarla karşılaştırılmış ve uyumlu olduğu gözlenmiştir. Ayrıca GATE simülasyonu ile elde edilen toplam gama verim eğrilerinin fit parametreleri analitik denklemin elde edilmesi için bulunmuştur.

\section{MALZEME VE YÖNTEM}

\subsection{PW Tipi Dedektör Sistemi}

PW dedektör sistemleri farklı fiziksel ve optiksel özelliklere sahip olan en az iki farklı sintilasyon malzemesinin bir araya getirilmesi ile oluşturulan dedektörlerdir. İki farklı sintilasyon malzemesinin radyasyona vermiş oldukları cevabın (yani bozunma zamanının) farklılığından dolayı elde edilen sinyallerin şekilleri farklı olur. Bu farklılık kullanılarak hangi enerjideki radyasyonun hangi sintilasyonla etkileşime girdiği tespit edilebilir. Bu tip bir dedektör sisteminin gösterimi ve tutturucu yardımı ile dedektör-kaynak mesafesinin ayarlanması Şekil 1. de verildiği gibidir.
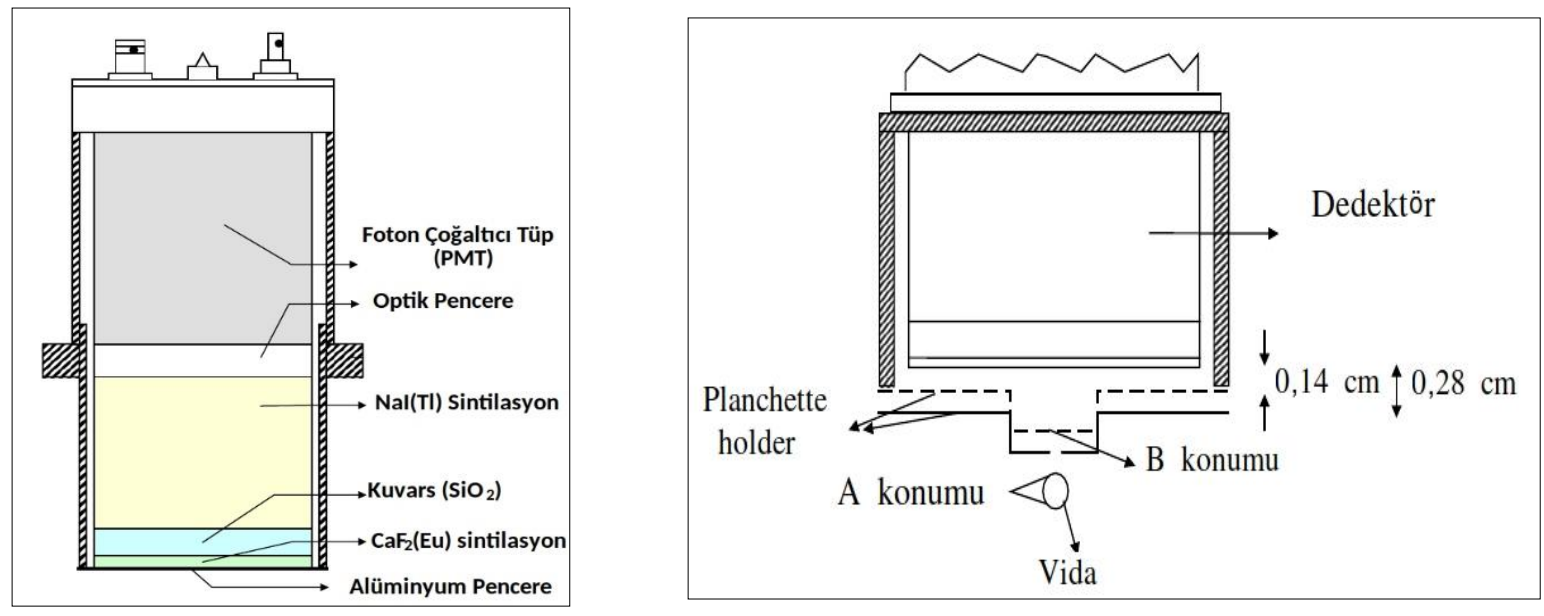

Şekil 1. Fosfor-Sandviç (LB 1000-PW) tipi sintilasyon dedektör sisteminin şematik gösterimi ve tutturucuyla dedektör kaynak arasındaki mesafenin ayarlanmasının gösterimi $[1,14]$.

$\mathrm{Bu}$ çalışmada kullanılan PW dedektör sistemi ince bir tabaka halindeki $\mathrm{CaF}_{2}(\mathrm{Eu})$ sintilatörü ile kalın bir $\mathrm{NaI}(\mathrm{Tl})$ sintilasyon malzemesinin optiksel olarak bir araya getirilmesinden oluşmuştur. İki sintilasyon malzemesinin ortasına etkileşimler sonucunda oluşacak yüklü parçacıkları durdurup NaI(Tl) kısmına geçişini engellemek için $\mathrm{SiO}_{2}$-Kuvars malzeme bulunmaktadır [1]. Ayrıca optiksel olarak bir araya getirilmesi; ilk sintilasyon malzemesinde oluşan görünebilir dalga boyundaki fotonların NaI(Tl) kısmına geçişine izin vererek PMT ile ilk sintilasyonda ki sinyallerin algılanabilmesini sağlamaktadır [15]. Yaklaşık olarak birkaç yüz mikron kalınlığındaki ince bir alüminyum kapsül içerisine sintilasyon malzemelerinin birleşimi hapsedilmiştir [1,14]. Bu kapsül ortamdaki ışığın dedektör içerisine girişini engellediği gibi aynı zamanda da radyasyonla etkileşim sonrasında sintilasyon malzemesi içerisinde oluşan görülebilir dalga boyundaki fotonların dedektörden dışarıya çıkışına da engel olmaktadır. Kısaca alüminyum kapsül burada yansitıcı olarak görev yapmaktadır. GATE simülasyonunda modellenen PW dedektör sisteminin bileşenlerinin bazı fiziksel ve optiksel özellikleri Tablo 1'de listelendiği gibidir. 
Tablo 1. PW dedektörünü oluşturan kuvars ve sintilasyon malzemelerin bazı optiksel ve fiziksel özelliklerinin listesi [1].

\begin{tabular}{ccccc}
\hline \hline Materyal & $\begin{array}{c}\text { Bozunma } \\
\text { zamanı }(\mu \mathrm{s})\end{array}$ & $\begin{array}{c}\text { Yoğunluk } \\
\left(\mathrm{gr} / \mathrm{cm}^{3}\right)\end{array}$ & Çap $(\mathrm{cm})$ & Kalınlık $(\mathrm{cm})$ \\
\hline \hline $\mathrm{CaF}_{2}(\mathrm{Eu})$ & 0,94 & 3,18 & 5,08 & 0,00635 \\
\hline \hline $\mathrm{NaI}(\mathrm{Tl})$ & 0,23 & 3,67 & 5,08 & 5,08 \\
\hline \hline $\mathrm{SiO}_{2}-\mathrm{Kuvars}$ & - & 2,65 & 5,08 & 0,3175 \\
\hline \hline
\end{tabular}

\subsection{Dedektör Verimliliği ve Gama Verimliliği Eğrisi}

Deneysel ölçümlerde ve bazı nükleer reaksiyonların ölçümünde mutlaka kullanılacak dedektör sisteminin enerji kalibrasyonlarının yanında dedektör verimliliği kalibrasyonlarının da yapılması gereklidir. Bir dedektörün verimliliği dedektör tarafından ölçülen sayımın radyoaktif kaynaktan yayınlanan radyasyon sayısına oranı ile bulunur. Herhangi bir dedektör sisteminin cevap verme özelliği incelendiğinde; toplam ve pik verimi olmak üzere iki dedeksiyon verimi vardır. Toplam verim enerjinin hangi değerde olduğuna bakmadan bütün etkileşimlerin kaydedildiği spektrumun tamamı ile ilgi iken pik verimi ise belirli bir eşik değerinin üzerindeki ve belirli bir enerji aralığındaki sinyallerle ilgilidir [16]. Toplam verim ifadesi Denklem 1'deki gibi gösterilir. Buradaki N kaynak tarafından gönderilen toplam gamaların sayısı iken, $\mathrm{N}_{\mathrm{D}}$ ise sintilasyon dedektörü tarafından sinyal olarak ölçülen tüm fotonların sayısıdır.

$\varepsilon_{\text {toplam }}=\frac{N_{D}}{N}$

Dedektör sisteminin toplam gama sayım verimliliğini tüm gama enerjileri için deneysel olarak belirlemek sınırlı sayıda tek enerjili gama yayınlayan radyoizotopların olmasından dolayı neredeyse imkansızdır $[1,11]$. Deneysel olarak elde edilen sınırlı sayıdaki gama sayım verimliliği aşağıda verilen denklemdeki fonksiyonla fit edilerek elde edilen analitik denklem verim kalibrasyonunda kullanılabilir.

$$
\begin{aligned}
& \varepsilon=\exp \left[\left(P_{0}+P_{1} x+P_{2} x^{2}\right)^{-P_{3}}+\left(P_{4}+P_{5} y+P_{6} y^{2}\right)^{-P_{3}}\right]^{\left(-\frac{1}{P_{3}}\right)} \\
& x=\log \left(\frac{E_{y}}{E_{1}}\right) \\
& y=\log \left(\frac{E_{y}}{E_{2}}\right)
\end{aligned}
$$

Denklem 3 ve 4'de bulunan; E $\gamma$-gamanın enerjisi, $E_{1}$ düşük enerji sabiti $(100 \mathrm{keV})$ ve $\mathrm{E}_{2}$ ise yüksek enerji sabiti (1000 keV) olarak ifade edilir [15]. Denklem 2'deki $\mathrm{P}_{4}, \mathrm{P}_{5}$ ve $\mathrm{P}_{6}$ dedektörün yüksek enerjideki toplam gama sayım verimliliği olarak ifade edilirken $\mathrm{P}_{0}, \mathrm{P}_{1}$ ve $\mathrm{P}_{2}$ ise düşük enerjideki verimliliğidir. $\mathrm{Bu}$ parameterelerden $\mathrm{P}_{2}$ göz ardı edilebilir [15,17-18]. Düşük ve yüksek enerji verimliliği bölgesinin arasında kalan bölgeyi $\mathrm{P}_{3}$ parametresi temsil eder. $\mathrm{P}_{3}$ 'ün büyük olması iki bölge arasındaki dönüşün keskin olduğunu gösterirken, küçük olması durumunda ise daha yavaş bir dönüşün olacağını gösterir [15]. 


\subsection{GATE Simülasyonunda PW Dedektörünün Modellenmesi}

GATE simülasyon programında Şekil 1'de gösterildiği gibi sintilasyon malzemeleri ve kuvars $\left(\mathrm{SiO}_{2}\right)$ Geant4 formatına uygun bir şekilde malzeme listesine tanımlanmıştır. Tablo 1'de özellikleri ve boyutları listelendiği gibi PW dedektör sistemi simülasyonda modellenmiştir. Silindir şeklindeki iki farklı malzemeden oluşturulmuş fosfor-sandviç (PW) tipi sintilasyon dedektör sisteminin Geant4' da gösterimi Şekil 2'de gösterildiği gibidir.

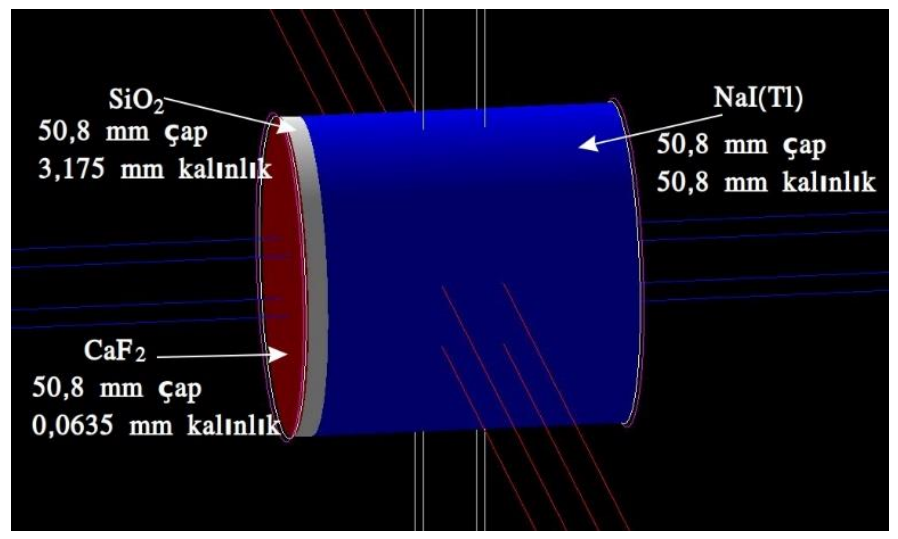

Şekil 2. Geant4 tabanlı çalışan GATE simülasyon programında PW tipi dedektör sisteminin gösterimi. Silindir şeklinde 5,08 cm çapında ve uzunluğundaki NaI(Tl) sintilasyon malzemesi (mavi) önüne 0,3175 cm kalınlığında kuvars $\left(\mathrm{SiO}_{2}\right)$ (gri) malzeme konumlandırılmıştır. $\mathrm{SiO}_{2}$ materyalinin diğer ucuna 0,00635 $\mathrm{cm}$ kalınlığındaki $\mathrm{CaF}_{2}$ (bordo) sintilasyon malzemesi konularak iki farklı sintilatör kuvars ile optiksel olarak birbirleriyle birleştirilmesi sağlanmıştır.

PW dedektör sisteminin geometrisi ve materyallerin özellikleri Geant4 formatına uygun bir şekilde tanımlandıktan sonra nokta ve disk şeklinde iki farklı kaynak geometrisi modellenmiştir (Şekil 3). Bu foton kaynaklarından yayınlanan gama sayısı bir milyon olarak sabitlenmiş ve izotropik bir şekilde fotonların saçılması sağlanmıştır. Monte Carlo'da oluşturulan random (rastgele) sayılar'dan dolayı ortaya çıkan istatistiksel dalgalanmaları azaltabilmek için en az 1000000 foton gönderilmesi gerektiği için 1000000 foton kullanılmıştır. Dedektör ile kaynak arasında üç farklı mesafe konumlandırması yapılarak 50-3000 $\mathrm{keV}$ aralığındaki farklı enerjilerde gama kaynakları kullanılmıştır.

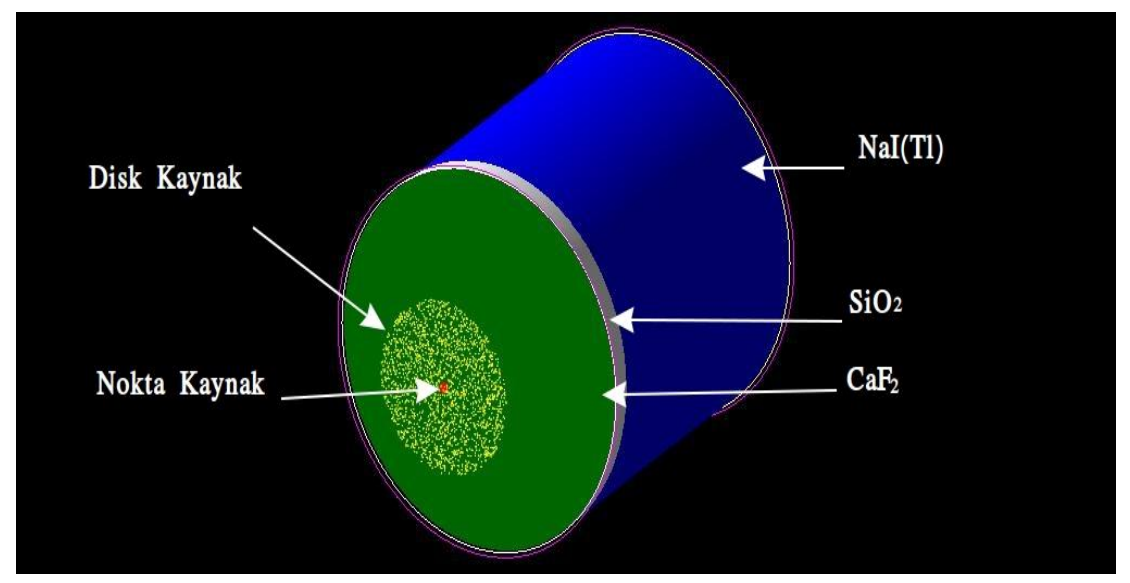

Şekil 3. Nokta ve disk kaynağın Geant4'da gösterimi. Nokta kaynak dedektörün önünde $0,43 \mathrm{~cm}$ mesafeyle konumlandırılan kırmızı renkle gösterilirken sarı renkle gösterilen noktalar kümesi ise $1,17 \mathrm{~cm}$ yarıçaplı disk kaynă̆ın gösterimidir. 
Nokta kaynaktan saçılan fotonların izlediği yolların gösterimi Şekil 4'deki gibidir. Burada ki yeşil çizgiler fotonları temsil eder ve bazı fotonlar dedektör ile hiçbir etkileşime girmeden gelip giderken bazılar ise dedektördeki sintilasyon malzemeleri ile etkileşime girerek sinyal olarak algılanırlar. Geant4'da kırmızı renk ise fotonların etkileşimde bulunduğu ortamdaki elektronların gösteriminde kullanılır.

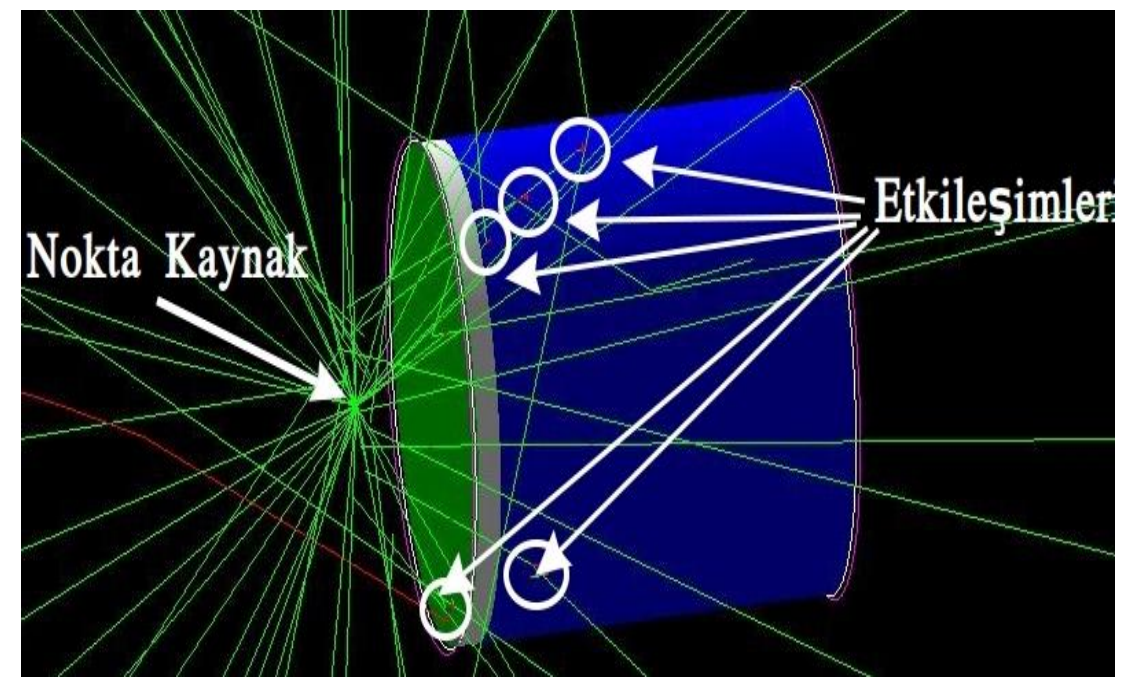

Şekil 4. Nokta kaynaktan yayınlanan 50 adet fotonun dedektör ile etkileşime girdiği yerler ve fotonların izlerinin gösterilmesi. Yeşil tek bir odak noktasından gelen (nokta kaynak) doğrusal çizgiler Geant4'da fotonları temsil ederken, kırmızı noktalar ise fotonların etkileşime girdikleri ortamdaki elektronları temsil etmektedir.

\section{BULGULAR VE TARTIŞMA}

İnce $\mathrm{CaF}_{2}(\mathrm{Eu})$ ile kalın $\mathrm{NaI}(\mathrm{Tl})$ sintilatör malzemelerinin optiksel olarak birleşiminden elde edilen dedektör sisteminin geometrisi Geant4 tabanlı çalışan GATE simülasyon programında modellendikten sonra dedektörün gama verimliliğini elde edebilmek için 50 keV'den 3000 keV'e kadar tek enerjili ve izotropik olacak şekilde fotonlar tek tek gönderilerek dedektör tarafından sinyale çevrilen sayımlar bulunmuştur. Her bir foton kaynağından bir milyon adet gama-ışını yayımlanmıştır ve dedektör tarafından algılanan toplam sinyalin radyasyon kaynağından çıkan toplam foton sayısına oranı dedektörün toplam verimliliğini vermiştir. GATE simülasyonunda elde edilen sonuçlar Tablo 2, Tablo 3 ve Tablo 4'de listelenmiştir. Tablo 2 'de kullanılan foton kaynağı noktasal kaynak olup dedektör ile kaynak arasındaki mesafe 0,43 cm, 0,87 $\mathrm{cm}$ ve $1,05 \mathrm{~cm}$ olacak şekilde ayarlanmıştır. 
Tablo 2. NaI-CaF $2(\mathrm{Eu})$ tipi dedektör sistemi için GATE simülasyonunda elde edilen dedektör verimliliğinin literatürdeki değerlerle karşılaştırması. Nokta kaynak tarafından farklı enerjilerde yayınlanan fotonların silindir şeklindeki fosfor-sandviç tipi dedektör için farklı kaynak dedektör mesafelerinde elde edilen toplam sayım verimliliği.

\begin{tabular}{|c|c|c|c|c|c|c|c|c|c|}
\hline \multirow[b]{2}{*}{$\begin{array}{l}\text { Enerji } \\
(\mathbf{k e V})\end{array}$} & \multicolumn{3}{|c|}{$D=0,43 \mathrm{~cm}$} & \multicolumn{3}{|c|}{$\mathrm{D}=0,87 \mathrm{~cm}$} & \multicolumn{3}{|c|}{$D=1,05 \mathrm{~cm}$} \\
\hline & GATE & $\begin{array}{l}\text { S.Yalçın } \\
\text { et al. [1] }\end{array}$ & $\begin{array}{c}\text { M.I. } \\
\text { Abbas et } \\
\text { al. [18] }\end{array}$ & GATE & $\begin{array}{l}\text { S.Yalçın } \\
\text { et al. [1] }\end{array}$ & $\begin{array}{c}\text { M.I. Abbas } \\
\text { et al. [18] }\end{array}$ & GATE & $\begin{array}{l}\text { S.Yalçın } \\
\text { et al. [1] }\end{array}$ & $\begin{array}{c}\text { M.I. } \\
\text { Abbas et } \\
\text { al. }[18]\end{array}$ \\
\hline 50 & 0,2337 & 0,2217 & 0,2214 & 0,1899 & 0,1892 & 0,1893 & 0,1746 & 0,1757 & 0,1757 \\
\hline 60 & 0,2554 & 0,2447 & 0,2445 & 0,2043 & 0,2061 & 0,2062 & 0,1873 & 0,1908 & 0,1906 \\
\hline 80 & 0,2693 & 0,2647 & 0,2648 & 0,2143 & 0,2199 & 0,2199 & 0,1950 & 0,2025 & 0,2023 \\
\hline 100 & 0,2709 & 0,2725 & 0,2724 & 0,2138 & 0,2234 & 0,2235 & 0,1941 & 0,2049 & 0,2049 \\
\hline 150 & 0,2586 & 0,2677 & 0,2680 & 0,2017 & 0,2140 & 0,2140 & 0,1825 & 0,1946 & 0,1948 \\
\hline 200 & 0,2371 & 0,2474 & 0,2476 & 0,1837 & 0,1940 & 0,1942 & 0,1665 & 0,1760 & 0,1760 \\
\hline 300 & 0,1989 & 0,2037 & 0,2041 & 0,1532 & 0,1578 & 0,1580 & 0,1384 & 0,1427 & 0,1430 \\
\hline 400 & 0,1749 & 0,1777 & 0,1776 & 0,1346 & 0,1370 & 0,1370 & 0,1217 & 0,1239 & 0,1239 \\
\hline 500 & 0,1595 & 0,1610 & 0,1611 & 0,1224 & 0,1241 & 0,1241 & 0,1109 & 0,1122 & 0,1122 \\
\hline 600 & 0,1489 & 0,1498 & 0,1499 & 0,1142 & 0,1153 & 0,1153 & 0,1032 & 0,1042 & 0,1042 \\
\hline 662 & 0,1427 & 0,1443 & 0,1443 & 0,1098 & 0,1110 & 0,1109 & 0,0994 & 0,1003 & 0,1003 \\
\hline 800 & 0,1335 & 0,1348 & 0,1347 & 0,1028 & 0,1034 & 0,1035 & 0,0932 & 0,0936 & 0,0935 \\
\hline 1000 & 0,1236 & 0,1247 & 0,1241 & 0,0949 & 0,0957 & 0,0952 & 0,0864 & 0,0865 & 0,0861 \\
\hline 1500 & 0,1074 & 0,1077 & 0,1070 & 0,0834 & 0,0827 & 0,0821 & 0,0749 & 0,0747 & 0,0742 \\
\hline 2000 & 0,0997 & 0,0993 & 0,0984 & 0,0771 & 0,0761 & 0,0754 & 0,0692 & 0,0688 & 0,0682 \\
\hline 3000 & 0,0912 & 0,0917 & 0,0910 & 0,0705 & 0,0701 & 0,0697 & 0,0637 & 0,0633 & 0,0630 \\
\hline
\end{tabular}

Tablo 3 ve Tablo 4' de ise sırası ile 1,17 cm ve 2,51 cm'lik iki farklı yarıçapa sahip disk şeklindeki gama kaynakları kullanılmıştır. Bu foton kaynakları kullanılarak elde edilen sonuçlar yine üç farklı dedektör kaynak mesafeleri için toplam gama verimliliği hesaplanarak tablolarda listelenmiştir. Ayrıca GATE simülasyonu ile bulunan PW dedektörünün toplam gama verimliliği değerleri literatürdeki sonuçlarla karşılaştırılmıştır. 
Tablo $3 \mathrm{NaI}_{-} \mathrm{CaF}_{2}(\mathrm{Eu})$ tipi dedektör sistemi için GATE simülasyonunda elde edilen dedektör verimliliğinin literatürdeki değerlerle karşılaştırması. Yarıçap1 1,17 cm olan disk şeklindeki kaynak tarafından farklı enerjilerde yayınlanan fotonların silindir şeklindeki fosfor-sandviç tipi dedektör için farklı kaynak dedektör mesafelerinde elde edilen toplam sayım verimliliği.

\begin{tabular}{|c|c|c|c|c|c|c|c|c|c|}
\hline \multirow[b]{2}{*}{$\begin{array}{l}\text { Enerji } \\
(\mathrm{keV})\end{array}$} & \multicolumn{3}{|c|}{$D=0,43 \mathrm{~cm}$} & \multicolumn{3}{|c|}{$D=0,87 \mathrm{~cm}$} & \multicolumn{3}{|c|}{$D=1,05 \mathrm{~cm}$} \\
\hline & GATE & $\begin{array}{l}\text { S.Yalçın } \\
\text { et al. [1] }\end{array}$ & $\begin{array}{c}\text { M.I. } \\
\text { Abbas et } \\
\text { al. [18] }\end{array}$ & GATE & $\begin{array}{l}\text { S.Yalçın } \\
\text { et al. [1] }\end{array}$ & $\begin{array}{c}\text { M.I. } \\
\text { Abbas et } \\
\text { al. }[18]\end{array}$ & GATE & $\begin{array}{l}\text { S.Yalçın } \\
\text { et al. [1] }\end{array}$ & $\begin{array}{c}\text { M.I. } \\
\text { Abbas et } \\
\text { al. }[18]\end{array}$ \\
\hline 50 & 0,2239 & 0,2158 & 0,2157 & 0,1804 & 0,1813 & 0,1814 & 0,1654 & 0,1678 & 0,1677 \\
\hline 60 & 0,2441 & 0,2379 & 0,2379 & 0,1945 & 0,1973 & 0,1975 & 0,1774 & 0,1818 & 0,1818 \\
\hline 80 & 0,2574 & 0,2569 & 0,2569 & 0,2031 & 0,2101 & 0,2102 & 0,1849 & 0,1926 & 0,1927 \\
\hline 100 & 0,2584 & 0,2636 & 0,2635 & 0,2028 & 0,2132 & 0,2133 & 0,1845 & 0,1949 & 0,1949 \\
\hline 150 & 0,2458 & 0,2569 & 0,2570 & 0,1907 & 0,2035 & 0,2033 & 0,1733 & 0,1847 & 0,1848 \\
\hline 200 & 0,2447 & 0,2362 & 0,2363 & 0,1749 & 0,1843 & 0,1844 & 0,1583 & 0,1670 & 0,1671 \\
\hline 300 & 0,1898 & 0,1944 & 0,1946 & 0,1461 & 0,1504 & 0,1505 & 0,1330 & 0,1362 & 0,1363 \\
\hline 400 & 0,1666 & 0,1695 & 0,1695 & 0,1282 & 0,1306 & 0,1308 & 0,1161 & 0,1184 & 0,1183 \\
\hline 500 & 0,1519 & 0,1539 & 0,1539 & 0,1176 & 0,1186 & 0,1186 & 0,1062 & 0,1072 & 0,1073 \\
\hline 600 & 0,1419 & 0,1406 & 0,1433 & 0,1089 & 0,1102 & 0,1103 & 0,0988 & 0,0997 & 0,0998 \\
\hline 662 & 0,1363 & 0,1380 & 0,1380 & 0,1050 & 0,1064 & 0,1061 & 0,0952 & 0,0961 & 0,0960 \\
\hline 800 & 0,1275 & 0,1290 & 0,1289 & 0,0989 & 0,0992 & 0,0991 & 0,0891 & 0,0897 & 0,0897 \\
\hline 1000 & 0,1186 & 0,1194 & 0,1188 & 0,0911 & 0,0917 & 0,0913 & 0,0831 & 0,0829 & 0,0826 \\
\hline 1500 & 0,1024 & 0,1033 & 0,1026 & 0,0800 & 0,0794 & 0,0787 & 0,0726 & 0,0717 & 0,0712 \\
\hline 2000 & 0,0956 & 0,0952 & 0,0944 & 0,0736 & 0,0730 & 0,0724 & 0,0671 & 0,0661 & 0,0655 \\
\hline 3000 & 0,0885 & 0,0879 & 0,0872 & 0,0677 & 0,0674 & 0,0669 & 0,0614 & 0,0609 & 0,0605 \\
\hline
\end{tabular}


Tablo 4. NaI-CaF $(\mathrm{Eu})$ tipi dedektör sistemi için GATE simülasyonunda elde edilen dedektör verimliliğinin literatürdeki değerlerle karşılaştırması. Yarıçap1 2,51 cm olan disk şeklindeki kaynak tarafından farklı enerjilerde yayınlanan fotonların silindir şeklindeki fosfor-sandviç tipi dedektör için farklı kaynak dedektör mesafelerinde elde edilen toplam sayım verimliliği.

\begin{tabular}{|c|c|c|c|c|c|c|c|c|c|}
\hline \multirow[b]{2}{*}{$\begin{array}{l}\text { Enerji } \\
(\mathrm{keV})\end{array}$} & \multicolumn{3}{|c|}{$D=0,43 \mathrm{~cm}$} & \multicolumn{3}{|c|}{$D=0,87 \mathrm{~cm}$} & \multicolumn{3}{|c|}{$D=1,05 \mathrm{~cm}$} \\
\hline & GATE & $\begin{array}{l}\text { S.Yalçın } \\
\text { et al. [1] }\end{array}$ & $\begin{array}{c}\text { M.I. } \\
\text { Abbas et } \\
\text { al. }[18]\end{array}$ & GATE & $\begin{array}{l}\text { S.Yalçın } \\
\text { et al. [1] }\end{array}$ & $\begin{array}{c}\text { M.I. } \\
\text { Abbas et } \\
\text { al. }[18]\end{array}$ & GATE & $\begin{array}{l}\text { S.Yalçın } \\
\text { et al. [1] }\end{array}$ & $\begin{array}{c}\text { M.I. } \\
\text { Abbas et } \\
\text { al. }[18]\end{array}$ \\
\hline 50 & 0,1792 & 0,1736 & 0,1764 & 0,1448 & 0,1447 & 0,1447 & 0,1329 & 0,1334 & 0,1334 \\
\hline 60 & 0,1956 & 0,1938 & 0,1940 & 0,1562 & 0,1574 & 0,1575 & 0,1436 & 0,1450 & 0,1449 \\
\hline 80 & 0,2061 & 0,2085 & 0,2084 & 0,1633 & 0,1675 & 0,1676 & 0,1499 & 0,1536 & 0,1538 \\
\hline 100 & 0,2066 & 0,2124 & 0,2125 & 0,1629 & 0,1701 & 0,1700 & 0,1489 & 0,1557 & 0,1557 \\
\hline 150 & 0,1967 & 0,2052 & 0,2051 & 0,1551 & 0,1625 & 0,1627 & 0,1418 & 0,1787 & 0,1487 \\
\hline 200 & 0,1820 & 0,1892 & 0,1891 & 0,1431 & 0,1493 & 0,1492 & 0,1308 & 0,1360 & 0,1363 \\
\hline 300 & 0,1555 & 0,1582 & 0,1582 & 0,1220 & 0,1244 & 0,1243 & 0,1117 & 0,1134 & 0,1135 \\
\hline 400 & 0,1375 & 0,1391 & 0,1391 & 0,1081 & 0,1091 & 0,1092 & 0,0987 & 0,0996 & 0,0996 \\
\hline 500 & 0,1260 & 0,1271 & 0,1271 & 0,0992 & 0,0996 & 0,0996 & 0,0903 & 0,0909 & 0,0909 \\
\hline 600 & 0,1184 & 0,1187 & 0,1187 & 0,0928 & 0,0930 & 0,0930 & 0,0849 & 0,0849 & 0,0849 \\
\hline 662 & 0,1144 & 0,1145 & 0,1145 & 0,0899 & 0,0898 & 0,8970 & 0,0819 & 0,0819 & 0,0818 \\
\hline 800 & 0,1077 & 0,1074 & 0,1074 & 0,0846 & 0,0840 & 0,0840 & 0,0772 & 0,0766 & 0,0766 \\
\hline 1000 & 0,0997 & 0,0999 & 0,0993 & 0,0786 & 0,0781 & 0,0776 & 0,0716 & 0,0711 & 0,0708 \\
\hline 1500 & 0,0873 & 0,0868 & 0,0861 & 0,0690 & 0,0678 & 0,0673 & 0,0626 & 0,0618 & 0,0614 \\
\hline 2000 & 0,0812 & 0,0802 & 0,0794 & 0,0635 & 0,0626 & 0,0620 & 0,0579 & 0,0571 & 0,0566 \\
\hline 3000 & 0,0754 & 0,0743 & 0,0736 & 0,0593 & 0,0580 & 0,0575 & 0,0536 & 0,0527 & 0,0524 \\
\hline
\end{tabular}

300-3000 keV enerjili fotonlar için GATE simülasyonuyla elde edilen sonuçlar literatürdeki sonuçlarla uyumludur ve \%2 lik bir sapmanın altında bulunmuştur. Ancak 50-300 keV arasında özellikle $150 \mathrm{keV}$ enerjili fotonlar için bulunan değerlerin literatürdeki değerlerle olan farklılığı maksimum \% 6.2'ye çıktığ gözlenmiştir. Düşük enerjideki farklılık random sayı üreticilerinden (istatistiksel) kaynaklanmış olabileceği gibi simülasyondaki modellemedeki optiksel fotonların üretiminden kaynaklı da olabilir. Ayrıca daha önceki Monte Carlo hesaplamalarında düşük enerjideki gamaların bazı etkileşimlerinin dikkate alınmaması veya XCOM'daki eski, güncel olmayan dataların kullanılmasından kaynaklı da olabileceği düşünülmektedir. Çünkü sintilasyon dedektöründeki farklı malzemeler için toplam zayıflama katsayıları literatürdeki çalışmalar da XCOM yazılımı ile elde edilmiştir (Berger ve Hubbell, 1999) [1]. GATE gibi kullanımı Geant4'a göre daha kolay ve medikal uygulamalar için özel olarak geliştirilmiş arayüz programının nükleer fiziğin dedektör uygulamalarında kullanılabilirliği bu çalışma ile bir kez daha gösterilmiş bulunmaktadır.

\section{SONUÇ}

Geant4 tabanlı çalışan GATE simülasyonuyla elde edilen PW dedektörü için toplam gama sayım verimliliği sonuçları nokta ve disk kaynak için sırası ile Şekil 5 ve Şekil 6' da gösterildiği gibi grafik haline getirilerek verimlilik eğrileri elde edilmiştir. Grafiklerde de göründügü gibi GATE sonuçları literatürdeki sonuçlarla oldukça uyumludur. Gözlemlenen özellikle 150 keV'deki farklılık simülasyondaki rastgele sayı 
üreticilerinden kaynaklanabileceği gibi optiksel foton üreticilerinden de kaynaklanacağı düşünülmektedir. Ayrıca literatürdeki kaynakların GATE kadar güncel olmamasından dolayı bu yazılımların bazı parametreleri kullanmadığı veya XCOM datalarının eski olmamasından dolayı da kaynaklanmış olabileceği düşünülmektedir. Yine de bu sapmaların \% 6,2’nin üzerinde olmadığı görülmektedir.

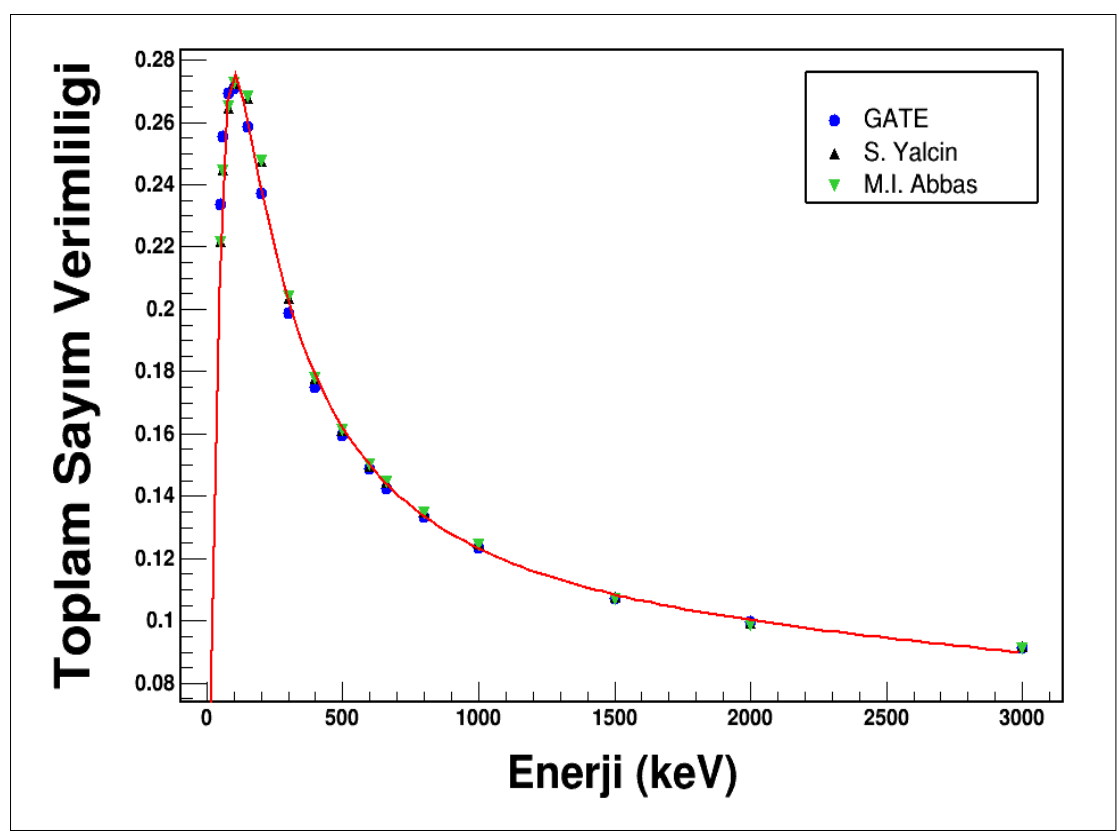

Şekil 5. Nokta kaynak için GATE simülasyonuyla elde edilen PW dedektörün gama verimliliği eğrisinin fit edilmiş hali. Mavi noktalar GATE simülasyonu ile elde edilen sonuçlarken siyah ve yeşil renkle temsil edilen veriler ise literatürdeki diğer iki sonuçları göstermektedir.

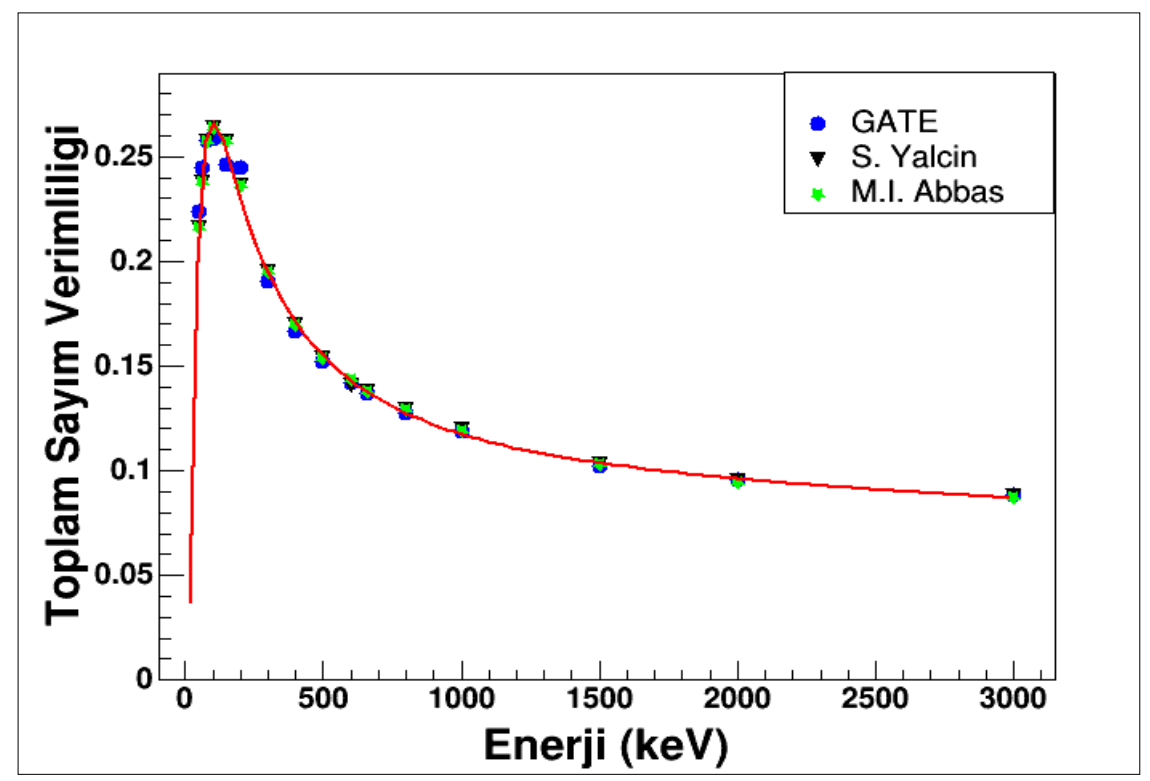

Şekil 6. 1,17 cm yarıçaplı ve disk şeklindeki kaynak için GATE simülasyonuyla elde edilen PW dedektörün toplam gama verimliliği eğrisinin fit edilmiş hali. Mavi noktalar GATE sonuçları iken siyah ve yeşil renkle temsil edilen veriler ise literatürdeki diğer iki sonucu göstermektedir.

Elde edilen PW dedektörünün toplam gama verimliliği eğrisi ROOT analiz programında Denklem 1'deki fonksiyona göre fit edilerek tüm parametreler Tablo 5'de verildiği gibi nokta ve disk kaynak için 
hesaplanmıştır. Bu parametreler kullanılarak PW tipi dedektorün toplam gama veriminin analitik denklemi bulunur ve bu denklem dedektörün verim kalibrasyonunun kolaylıkla yapılmasını sağlar.

Tablo 5. Nokta ve disk kaynak için elde edilen dedektör verimliliği değerlerinin fit edildikten sonra bulunan parametre değerleri.

\begin{tabular}{ccccccc}
\hline & \multicolumn{3}{c}{ Nokta Kaynak } & \multicolumn{3}{c}{ Disk Kaynak (r=1,17 cm) } \\
\cline { 2 - 7 } Fit & \multicolumn{3}{c}{$\mathbf{D}(\mathbf{c m})$} & & \multicolumn{3}{c}{ D (cm) } \\
\cline { 2 - 7 } Paremetreleri & $\mathbf{0 , 4 3}$ & $\mathbf{0 , 8 7}$ & $\mathbf{1 , 0 5}$ & $\mathbf{0 , 8 7}$ & $\mathbf{1 , 0 5}$ & $\mathbf{0 , 4 3}$ \\
\hline $\mathrm{P}_{0}$ & 8,6099 & 7,7011 & 7,6783 & 8,5600 & 8,2521 & 7,6453 \\
$\mathrm{P}_{1}$ & 2,7667 & 2,1807 & 2,1638 & 2,8900 & 2,8101 & 2,1754 \\
$\mathrm{P}_{2}$ & $-2,1500$ & $-2,1500$ & $-2,1500$ & $-2,1500$ & $-2,1500$ & $-2,1500$ \\
$\mathrm{P}_{3}$ & 1,7705 & 2,0938 & 1,9920 & 1,7700 & 1,8392 & 1,9553 \\
$\mathrm{P}_{4}$ & 7,3537 & 7,0000 & 7,0000 & 7,2200 & 7,2523 & 7,0000 \\
$\mathrm{P}_{5}$ & $-0,8816$ & $-0,0076$ & $-0,0023$ & $-0,9800$ & $-0,9517$ & $-0,0017$ \\
$\mathrm{P}_{6}$ & 2,0028 & 2,4978 & 2,5485 & 2,0000 & 2,2023 & 2,5568 \\
\hline
\end{tabular}

PW dedektörünün toplam gama veriminin uzaklığa ve gelen fotonun enerjisine bağlı olarak nasıl değiștiği Şekil 7'de verildiği gibi elde edilmiştir. Uzaklık arttıkça gama fotonunun dedektörle etkileşime girme olasılığı geometrik verimden dolayı azalacağından toplam verim düşmektedir. Gelen fotonun enerjisi arttıkça dedektördeki sintilasyon malzemesinin özelliğine bağlı olarak etkileşime girme olasıllı̆g da azalmaktadır. Enerji arttıkça etkileşime girmeden dedektöre girip çıkan foton sayısı da artmaktadır.

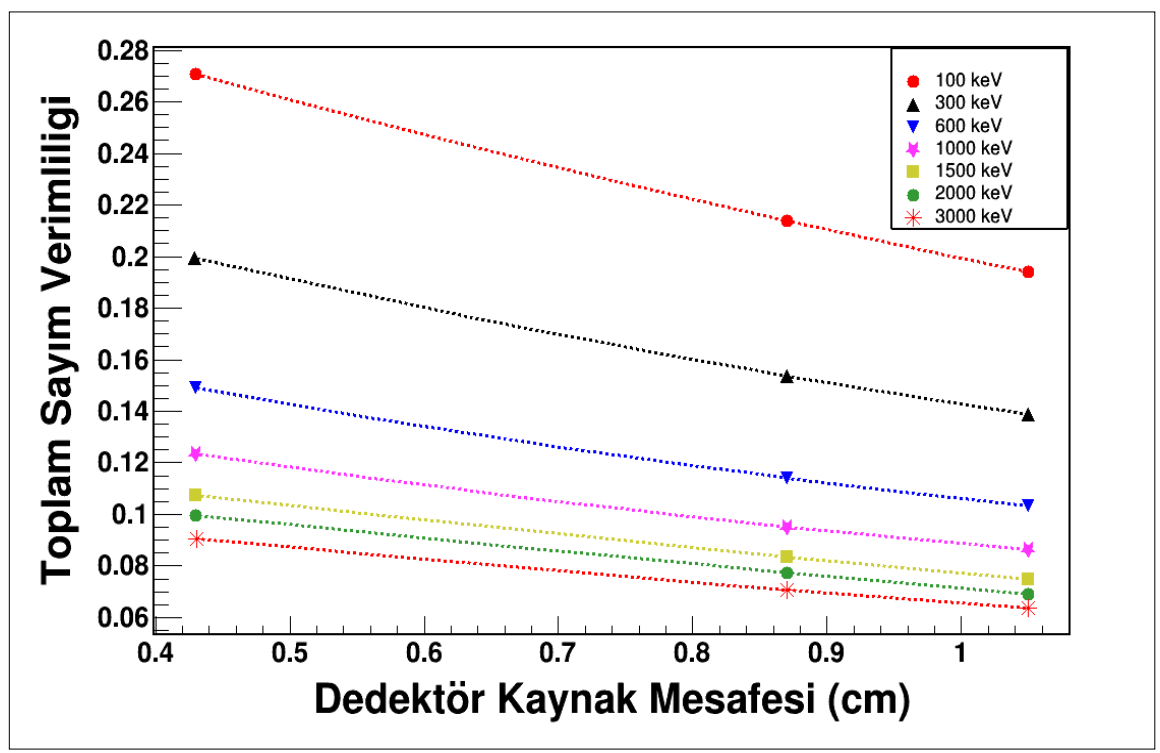

Şekil 7. Dedektör kaynak mesafesine göre GATE simülasyonu ile elde edilen toplam gama sayım verimliliğinin gelen fotonun enerjisine bağl1 olarak değişimi. 


\section{REFERANSLAR}

[1] Yalçın, S., Gurler, O., Gundoğdu, O., Kaynak, G. (2009). "Monte Carlo simulation of gamma-ray total counting efficiency for a Phoswich detector." Radiation Measurements 44, 80-85.

[2] B. Alemayehu, A. T. Farsoni, L. Ranjbar, E. M. Becker (2014). "A well-type phoswich detector for nuclear explosion monitoring” J Radioanal Nucl Chem 301, 323-332.

[3] Neha Dokania, Nanal, V., Singh, V., Katyan, N., Mathimalar, S., Pillay, R.G., Chakrabarty, D.R., Datar, V.M., Suresh, K., Mishra, G., Pose, M.S., Mishra, S., Deepak, P., Mukhopadhyay, S. (2012). "Characterisation of a $\mathrm{LaBr} 3$ (Ce)-NaI(Tl) Phoswich detector for high energy gamma rays."Proceedings of the DAE Symp. on Nucl. Phys. 57, 874-875.

[4] Olivier Dorvaux, (2016). "PARIS : A versatile detection array for low and high energy gamma-rays" 17th AGATA-Position Sensitive Germanium Detectors and application Workshop.

[5] Seiichi Yamamoto, Hiroyuki Ishibashi (2015). "Development of a three-layer phoswich alpha-betagamma imaging detector." Nuclear Instruments and Methods in Physics Research A 785, 129-134.

[6] Seiichi Yamamoto, Jun Hatazawa (2011). "Development of an alpha/beta/gamma detector for radiation monitoring.” Review of scientific Instruments 82(113503), 1-6.

[7] Sara Spadola (2017). "Development and evaluation of an intraoperative beta imaging probe for radioguided solid tumor surgery." Doktora Tezi Medical Physics, Université Paris-Saclay.

[8] Bipin Singh, Brendan, C., Stack, Jr., Samta Thacker, Valeriy Gaysinskiy, Twyla Bartel, Val Lowe, Steven Cool, Gerald Entine, Vivek Nagarkar (2013) "A Hand-Held Beta Imaging Probe for FDG.” Ann Nucl Med. 27(3), 203-208.

[9] Matthias, N. V. O., Daphne, D. D. R., Mick, M. W., Henk, G. V. D. P., Tobias, M., Fijs, W. B. V. L., (2019). "Recent advances in nuclear and hybrid detection modalities for image-guided surgery." Expert Review of Medical Devices 16(8), 711-734.

[10] Hamzawy A., (2010). "Simple analytical formula to calculate $\gamma$-ray cylindrical detectors efficiencies." Nuclear Instruments and Methods in Physics Research Section A 624 (1):124-129.

[11] Chuong, H.D., Nguyen, Q.H., Nguyen, T.M.L., Nguyen, V.H. (2019). "Validation of gamma scanning method for optimizing $\mathrm{NaI}(\mathrm{Tl})$ detector model in Monte Carlo simulation." Applied Radiation and Isotopes 149, 1-8.

[12] Yavuzkanat Nuray, Güngör Didem, Yalçın Sezai (2019). "The determination of the total efficiency for $\mathrm{NaI}(\mathrm{Tl})$ detector by GATE simulation.” BEU Journal of Science 8 (Special Issue), 37-45. https://dergipark.org.tr/tr/pub/bitlisfen/issue/51415/649129

[13] Open Gate Collaboration (2019). "Users Guide V8.0 From Wiki OpenGATE”. http://www.opengatecollaboration.org/sites/default/files/GATE-UsersGuideV8.0.pdf (Erişim Mayıs 2019).

[14] Saint-Gobain Crystals Data Sheet (2002-2019). "Phoswich Detectors For High Energy Backgrounds.” 
[15] Yavuzkanat Nuray, (2015). "Development of Novel scintillation Detection Techniques for Use in Nuclear Physics and Medical Applications." Doctor of Philosophy, The University of York, UK.

[16] Çelik Ahmet, (2017). "HPGe Gama Dedektörlerinde Soğurma Parametreleri ve Kristal Kalınlığının Belirlenmesi." Doktora Tezi, Karadeniz Teknik Üniversitesi, Türkiye.

[17] A software package for interactive graphical analysis of gamma-ray coincidence data( 152 Eu Fullenergy peak efficiency calibration); http://radware.phy.ornl.gov/gf3/gf3.html (Erişim: 12 Haziran 2015).

[18] Abbas Mahmoud I., Salam Noureddeen (2011). "Analytical expression to calculate total and fullenergy peak efficiencies for cylindrical phoswich and lanthanum bromide scintillation detectors." Radiation Measurements 46, 440-445. 